\title{
Eficiência Tecnológica, Forças Produtivas e Classes Sociais
}

\author{
Marcelo M. Doti* \\ Sinclair M. G. Guerra**
}

\section{INTRODUÇ̃̃o: FORÇAS PRODUTIVAS E CLASSES SOCIAIS}

Este texto se coloca em um momento histórico muito preciso: o das questões de produtividade social e eficiência do uso de recursos e, em especial, dos energéticos. Desta forma, dentro da mídia e dos discursos empresariais e mesmo oficial, ganha cada vez mais destaque a busca incessante de eficiência como o prognóstico de sucesso e de atividades econômicas bem sucedidas. Não se mostram, entretanto, os vínculos e as conexões, as determinações profundamente sociais desta eficiência. Em uma sociedade cada vez mais pragmática e marcada pelo domínio total e absoluto do capital em todos os sentidos e instâncias sociais (política, ideológica, cultural, geopolítica, econômica etc.), não se pode esquecer de verificar que a base da análise marxiana é econômica e que Marx insistia no caráter científico de sua pesquisa. Deve-se, também, ter em conta que o centro de desenvolvimento do pensamento de Marx não é a análise acadêmica, mas sim o objetivo máximo que é a superação do capitalismo. Porém, a sociedade futura não se pode pautar pela pobreza: o socialismo é o reino da riqueza. Questões sobre o desenvolvimento econômico se colocam aqui de forma nada sutil e os debates dos anos 1920, após a Revolução de Outubro na URSS, também. E isso,

${ }^{*}$. DE/FME/Unicamp.

${ }^{* *}$. DE/FEM/Unicamp.

1. Veja-se Daniel Aarão Reis Fillho, As Revoluções Russas e o Socialismo Soviético. São Paulo, Editora Unesp, 2003, p. 80 e segs.

Economia e sociedade no capitalismo contemporâneo

cadernos cemarx, nํㅜ - 2006 101 
por sua vez, acaba por colocar o problema das forças produtivas como um problema central para a análise marxiana da realidade e das possibilidades de uma sociedade socialista.

Na história do desenvolvimento das sociedades humanas, nenhum problema colocado pela específica práxis deixa de encontrar resposta. Confusa ou imprecisa, há sempre uma resposta. Esse tipo de processo se assemelha muito à própria evolução da vida por meio da seleção natural. Sempre é dada uma resposta aos problemas que a sociedade coloca ainda nos primeiros estágios do desenvolvimento de todas as sociedades humanas. Elaborar, a partir da subjetividade, uma resposta à objetividade é característica, como se disse, do próprio processo de desenvolvimento de qualquer complexo existente. Nas sociedades humanas as formas de desenvolvimento social são respostas à objetividade que se colocam em dado estágio desse mesmo desenvolvimento. Isso se torna mais característico quando se trata da sociedade capitalista e de seu desenvolvimento.

Em função da forma de produção do excedente deste modo de produção e de como a riqueza é concentrada, tem-se uma dada estrutura de classes e de relações sociais estabelecidas nesta sociedade. A reprodução destas relações de classe implica produção de riqueza abstrata, mera reprodução do sistema, mas sempre atendendo ao consumidor. Este se coloca, então, como a forma de alocação de recursos e centro das trocas sociais e de todas as relações sociais. A mediação total da sociedade é feita por meio do mercado: é o "metabolismo" ao qual se faz muita referência². Percebe-se que a produção para o mercado como condição primeira de reproduzir o sistema e produzir riqueza abstrata implica quantidades crescentes de mercadorias. O desdobramento do processo é bastante evidente: desenvolver tecnologias que aumentem a eficiência produtiva do sistema. Em um sentido bem estrito, fazer avançar as forças produtivas para que o sistema se reproduza de forma ampliada.

O conceito de forças produtivas vai muito além, como insinuado anteriormente, da inserção de novas tecnologias na produção. Como forças produtivas deve-se en-

2. Interessante notar que em outras formações socias sujeitadas a outros modos de produção não tinham suas relações sociais mediadas pelo mercado. Este se impõe de forma tão poderosa como ideologia e como materialidade crescente de mercadorias à nossa vista que é quase impossível pensar em formações sociais nas quais o mercado não era o centro das mediações. Formações nas quais o próprio espaço, por exemplo, não era determinado pela forma específica da produção e do mercado. É o caso das formações sociais da Antigüidade e do caso bem particular da polis grega. Leonardo V. Benévolo, História da Cidade. São Paulo, Editora Perspectiva, 2001, capítulo 4, especialmente p. 77-78.

102 Eficiência Tecnológica, Forças Produtivas e Classes Sociais 
tender todo o conjunto social que amplia a capacidade e a possibilidade de produção. O conceito de forças produtivas serve, então, como base para se formular um outro de caráter marxiano de civilização ${ }^{3}$. Por meio deste conceito de civilização estaria formulada uma elevação no padrão material e da materialidade social ${ }^{4}$. Também, o maior controle sobre as condições e uso dos recursos naturais, assim como de espaços antropogênicos mais complexos. Por esse motivo a elevação do patamar das forças produtivas implica estágio mais avançado do processo civilizatório ${ }^{5}$.

Ainda que o desenvolvimento das forças produtivas signifique um processo mais avançado na forma de produzir e controlar as condições naturais por meio de uma materialidade crescente e de espaços antropogênicos mais complexos, não se pode nunca deixar de entender que as mesmas se desenvolvem de maneira contraditória, elevando o patamar civilizatório e subordinando-se à estrutura de classes da sociedade da qual é reflexo. As forças produtivas estarão, sobretudo, subordinadas ao controle social de classe daqueles que detém os meios de produção. Logo o seu desenvolvimento pode se generalizar na forma de patamares civilizatórios mais elevados, como reflexo da necessidade de produção, concentração e acúmulo de riqueza por parte das classes dominantes e controladoras da sociedade e dos meios de produção. Um dos melhores exemplos para qualquer forma de civilização é o desenvolvimento dos transportes e comunicações. Modificam o espaço geográfico e possibilitam a integração social, especialmente na sociedade do capital na qual estas forças produtivas (transportes e comunicações) se fazem de forma mais intensa e rápida. No entanto, as mesmas não são produzidas como forma de elevar o patamar genérico de civilização, ou seja, conquistas humanas. São, na verdade, formas de aumentar o controle total sobre as condições de produção e concentrar e acumular mais riqueza, centralizando crescentemente o capital. Isso implica, por sua vez e de maneira direta, um controle

3. M. M. Doti, Reprodução Econômica e Energia. Tese de doutoramento não publicada, DE/FEM/UNICAMP, Campinas, 2005.

4. Materialidade é a base do conceito de civilização que se desenvolveu em capítulo da tese referida na nota 3. Por esta, entende-se a quantidade crescente de recursos naturais postas a disposição para o uso humano (valor de uso) em qualquer formação social. Em outros termos, a forma como se transforma a matéria tornando-a utilidade social. No modo de produção capitalista a materialidade social é gigantesca em função do acúmulo e concentração crescente de riqueza como determinação do mercado e como necessidade da reprodução do sistema (produção de riqueza abstrata).

5. Provém desta constatação e verdade a famosa apologia de Marx às forças produtivas do capital em seu Manifesto de 1848.

Economia e sociedade no capitalismo contemporâneo

cadernos cemarx, nํㅜ $2006 \quad 103$ 
cada vez maior das condições e dos recursos naturais por parte de alguns estratos sociais em detrimento de outros.

Esta estreita relação de forças produtivas e classes sociais é a base para pensar o socialismo. Porém, isso não se pode dar no reino de profunda miséria. Tem-se, então, que pensar nas condições políticas que possam tornar o objetivo máximo do marxismo realizável. A realização deste, articulada com as condições políticas possíveis, terá que resultar no controle social das forças produtivas. Só então a civilização se traduzirá em conquistas humanas.

\section{NATUREZA E A SOCIEDADE DO CAPITAL}

O desenvolvimento das forças produtivas serve como base para a articulação e a formação de um conceito de civilização. Explica-se isso pelo fato de que uma complexa cadeia de nexos e determinações é estabelecida entre forças produtivas e classes sociais ao mesmo tempo em que por meio das mesmas se adquire mais elevado grau de controle humano sobre a natureza. Em outros termos, maior controle das condições naturais significa precisamente uma materialidade mais sofisticada ao mesmo tempo em que esta é a expressão empírica, viva e explícita das relações sociais que se estabelecem na produção. As forças produtivas mais desenvolvidas correspondem a um maior controle sobre as condições naturais. Isso significa controlar o tempo de produção de materialidades mais complexas. Agir sobre o tempo e a matéria no sentido de produzir materialidades mais sofisticadas nada mais é que controlar a natureza. Trata-se do controle do tempo, do espaço e da matéria, assim como da utilização dos recursos energéticos e reprodução de determinado estágio de civilização amparado sobre um modo de produção e as relações sociais de classe correspondentes.

Impossível, então, entender toda a riqueza do conceito de forças produtivas se não se proceder à conexão do mesmo com o de civilização. Este, por sua vez, não pode ser um conceito cultural vago. Sua precisão está na percepção de que as forças produtivas são um dos elementos que o compõem, devendo, ainda, vir articulado com os conceitos de materialidade, de espaços antropogênicos e de controles naturais. Por este motivo que ao marxismo é imprescindível um conceito de natureza e o lugar da sociedade humana dentro da mesma. Especialmente quando se tem na civilização do capital aquela que mais modifica e controla as condições naturais na forma de uma materialidade mais complexa e extensiva, seja em seus espaços produtivos gigantes,

104 Eficiência Tecnológica, Forças Produtivas e Classes Sociais 
suas cidades ou em sua fenomenologia do capital - a expressão empírica do capital na forma de mercadorias ${ }^{6}$.

Sendo o capital a categoria fundamental sobre a qual se estrutura toda a sociedade capitalista, sua política e ideologia, o desenvolvimento das forças produtivas tem que se dar de forma intensa. O capital deve ser remunerado e garantir sua própria reprodução. Como tal, a produção de mercadorias se desenvolve em larga escala e para um crescente número de compradores. Reduzir o tempo de produção das mercadorias é possibilitar o incremento dos lucros e aumentar a reprodução, concentrar e centralizar ainda mais o capital bem como controlar elementos humanos e materiais: o trabalho, o tempo, o espaço, os recursos naturais.

\section{A PARTiCipaÇÃo da teCNOlogia E da CiênCIA.}

Neste momento histórico a questão da eficiência produtiva tem seu destaque. A tecnologia e a ciência se transformam intensa e crescentemente em aliados da produção e cada vez mais subordinados à mesma e a todas as necessidades do capital. Historicamente, pode-se refletir sobre as questões concernentes à ciência, à produção potencializada pelo desenvolvimento das forças produtivas e às soluções tecnológicas encontradas para dinamizá-la. Essas soluções terão formas e matizes diferentes à medida que se muda a conjuntura histórica e o nível de lucratividade (taxa de lucro) do capital.

Nas formações sociais pré-capitalistas não existia a mediação do capital: não sendo produção voltada para o mercado, não existiam grandes necessidades de elevar o padrão das forças produtivas e dos ritmos tecnológicos já que o acúmulo de riqueza não consistia na venda de mercadorias. Naquelas formações sociais não era necessário o controle estrito da produção e não se necessitava superar o tempo gasto com tal ou qual atividade e produzir quantidades crescentes em intervalos menores, elevando a produtividade. Logo, não se tinha a imperiosa necessidade de eficiência produtiva. A ciência e a tecnologia, então, eram adequadas para o controle da produção e a mediação com a natureza era menos pronunciada. O nível material

6. Em Marxé possível fazer a constatação deste conceito logo na primeira frase de 0 Capital: "A riqueza das sociedades em que domina o modo de produção capitalista aparece como uma 'imensa coleção de mercadorias', e a mercadoria individual como sua forma elementar" (Livro I, O Processo de Produção do Capital, São Paulo, Nova Cultural, “Os Economistas”, 1985, p. 45).

Economia e sociedade no capitalismo contemporâneo

cadernos cemarx, n-03-2006 105 
- no sentido de materialidade como conceito marxiano de civilização - dessas sociedades era menos desenvolvido.

O oposto se passa na sociedade do capital na qual o controle da produção é fundamental e elevar a produtividade é imperioso. Para isso, ciência, tecnologia e indústria vão se fundir numa síntese única e recente na história humana. Ainda que a industrialização já se tenha processado ao longo de todo o século, é só no fim do século XIX que essa síntese irá ocorrer. Mas, aqui um verdadeiro paradoxo entra pela janela quando parecia expulso pela porta. Na sociedade do capital, o controle da produção como forma de acumular riquezas elevou o patamar material ao desenvolver intensamente as forças produtivas. É dessa forma que a mediação entre natureza e sociedade pareceu ampliar-se ao pôr sobre o controle social de classe os recursos naturais, as fontes de energia, o espaço, o tempo e a matéria da qual se faz a própria vida. Controlar a natureza pareceu algo mais evidente. O sentido ideológico que isso assumiu foi mais profundo que controlar: dominar a natureza parecia a expressão adequada. A ideologia bíblica e medieval pareceu se colocar mais claramente ${ }^{8}$. Volta agora pela janela: o maior controle da natureza e a maior mediação com a mesma aparece como dependência natural de uma sociedade movida por uma contradição básica: a contradição de classe e o controle da produção por apenas uma destas. Partindo desta contradição fundamental, expressam-se as demais, inclusive a da dependência natural sob dois pontos de vista. Primeiro de tudo, evidente nas questões ecológicas, assumindo, por isso, caráter político. O outro pensado neste texto, é que por ser a produção o locus determinante do acúmulo de riquezas, a sociedade do capital tornou-se mais dependente das condições materiais, da materialidade não só produzida e vendida por ela - sob a forma de mercadoria. Tornou-se mais dependente da materialidade natural como as fontes de energia e sua irregular e desigual distribuição pelo espaço. O que se afastava, então, pela porta da frente - domínio sobre a natureza, "afastamento das barreiras naturais", etc. -- volta pela janela do quintal. A sociedade do capital produziu condições mais mediadas

7. J. D. Bernal, Ciencia e Industria en el Siglo XIX. Barcelona, Martinez Roca, $1^{\text {ạ }}$ ed., 1973 (Ver primeira parte).

8. Com isso, está-se dando ênfase ao caráter judaico-cristão de uma ideologia de domínio da natureza presente nas palavras do Gênesis que confere a Adão o poder de dominar e tomar toda a natureza, pois tudo fora feito para ele que é imagem e semelhança de Deus: é o antropocentrismo explícito que encontrará eco no humanismo marxista. Ver sobre o Gênesis I, 26-28 e J.-P. Délage, Une histoire de l'écologie. Paris, Ed. La Découverte, 1991, p. 25-6.

106 Eficiência Tecnológica, Forças Produtivas e Classes Sociais 
com a natureza e ao mesmo tempo tornou-se mais dependente da mesma em visível contradição dialética9.

\section{ConClusão E NECESSIDAde DA EMANCIPAÇÃo}

Sabe-se que os estágios iniciais do capitalismo correspondem a um longo processo histórico de acumulação por meio dos desenvolvimentos comerciais. Neste o acúmulo de riquezas e a centralização das mesmas vão possibilitar uma transformação até que surja a classe produtiva dos capitalistas industriais. Com estes, ao mesmo tempo, surgem outros interesses, o da classe produtora da riqueza por meio da venda da força de trabalho. Somente nesta sociedade será possível revolucionar de forma completa a produção na qual tudo se torna mercadoria com a formação de mercados mais amplos. O próprio trabalho se transforma em mercadoria sob a forma de força de trabalho. Porém, antes do surgimento da produção revolucionada pela máquina e o crescimento vertiginoso da composição orgânica do capital, é com a etapa comercial que ocorre o acúmulo de riquezas. Como nesta a riqueza se produz na circulação mercantil, é inevitável que as forças produtivas se desenvolvam de forma crescente por meio de inovações tecnológicas nas artes náuticas e de transportes tais como o astrolábio, o uso da bússola, o conhecimento dos ventos e das correntes marítimas em especial no hemisfério sul do planeta, as novas formas de embarcação etc.

Deve-se ter claro, no entanto, que todas essas formas tecnológicas e de desenvolvimento das forças produtivas estabelecem, de um lado, um novo padrão nascente de civilização: a do capital. Põem-se as bases para a civilização do capital de materialidade complexa e espaços antropogênicos cada vez maiores após o domínio da produção e da ciência pelo capital. Por outro lado, isso só se vai tornar possível, pois se trata de

9. Entende-se, assim, a fundamentação necessária do estudo da dialética da natureza. Ver sobre isso o pequeno e interessante livro de BROHM, Jean-Marie. 0 que é Dialética? Edições Antídoto, Lisboa, 1979, $1^{\text {a }}$ ed. Na p. 42, o autor mostra algumas passagens de Marx e Engels nas quais estão definidas claramente a articulação e 0 profundo elo de ligação entre a história e a natureza. Estas se condicionam e, no caso deste texto, a “mediação entre dialética natural e dialética histórica é dada pelo processo de produção". Tal acesso liga em definitivo o capital à natureza, por isso Marx e Engels insistem na fórmula de que só há uma ciência, a da história. Sobre essa questão de natureza e espaço geográfico é possível aferir o nível das discussões a partir de muitos autores entre os quais várias das obras de D. Harvey, O novo Imperialismo. São Paulo, Loyola, 2004. Ver também E. W. Soja, Geografias Pós-Modernas - A Reafirmação do Espaço na Teoria Social Crítica. Rio de Janeiro, Jorge Zahar Editores, 1ª ed., 1993 e Massimo Q̨auine, Marxismo e Geografia. São Paulo-Rio, Paz e Terra, 2a edição, 1991.

Economia e sociedade no capitalismo contemporâneo

cadernos cemarx, nํㅜ - $2006 \quad 107$ 
um acúmulo de riqueza em escala gigantesca e centralizada, levando à possibilidade de colocar mais trabalho humano (a fonte de toda a riqueza social) sob controle social dos que dominam a produção ${ }^{10}$. A transferência de riqueza de um setor para o outro é que permite o passo rumo ao controle da produção e, portanto, da Revolução Industrial.

Nesse momento de entrada do capitalismo em novo patamar histórico conformado às necessidades também renovadas de acumulação, presencia-se neste suas características sociais e produtivas básicas plenamente desenvolvidas: formação da classe trabalhadora e controle maior da produção. Desta forma ter-se-á um círculo de determinação dialética no qual o trabalho social é controlado pela produção. De alto a baixo a atividade do capital industrial e sua específica forma de produção e reprodução vão provocar uma das maiores revoluções produtivas da história da humanidade. Revolução só comparada com a neolítica na qual o H. sapiens pôs à sua disposição o controle dos vegetais e, concomitantemente, o dos animais. Na revolução agrícola a materialidade, a exterioridade natural, passou a ser controlada em determinados aspectos que eram possíveis, dadas as condições do momento tanto técnicas como econômicas. A Revolução Industrial e as transformações sociais originadas do capital se expressam em controle da materialidade, da exterioridade da matéria posta à disposição do homem. Atente-se, porém, que não se trata de um controle material em função de um projeto humano: é tão somente uma forma de controle da matéria com vistas à reprodução de classe de dado sistema produtivo.

Tem-se um crescimento quantitativo e qualitativo cada vez maior da produção por meio de forças produtivas mais desenvolvidas, com aumento da eficiência produtiva e do controle da ciência pelo capital. A socialização da produção eleva os padrões humanos de civilização. Somente na sociedade e civilização do capital é que pode surgir o conceito pleno de humanidade. Nunca se viu um tal padrão de materialidade e de controle das condições e dos recursos naturais.

Verifica-se, então, que as forças produtivas estarão em consonância com o seu momento histórico. As respostas às necessidades sociais e de acúmulo de riqueza, bem como de concentração e centralização do capital, elevarão a composição orgânica do mesmo. A ciência se subordina à produção e a eficiência se traduzirá em produzir

10. Deve-se ter claro que a atividade comercial não coincide com o capitalismo. Aqui se deixa apenas a indicação da distinção muito bem feita por Fernand Braudel, La Dinâmica del Capitalismo, Fondo de Cultura Económica, México, 1986, $1^{\text {ạ }}$ ed, p. 45 e segs.

108 Eficiência Tecnológica, Forças Produtivas e Classes Sociais 
mais se expressando também em aumento do poder do capital e do trabalho morto. A partir deste momento preciso e determinado da esfera produtiva chega-se às instâncias sociais e políticas com o poder decrescente da classe trabalhadora e da fragmentação do mundo do trabalho. O conceito de eficiência se traduz, na prática, em desemprego crescente e em novas formas de pensar a emancipação e os agentes transformadores e portadores desta.

Isso não é nada novo e já era colocada no século XIX por Marx, que vislumbrava todo o potencial produtivo desta sociedade. As frustradas revoluções do século XX parecem ter feito esmorecer a ideologia revolucionária. Em hipótese alguma, no entanto, se trata de falar em utopias $^{11}$. Deve-se ter clareza de alguns fatos para se trilhar o caminho essencial que conduz a uma teoria, nada nova, em novo momento histórico da emancipação. Em primeiro lugar, o capitalismo visto por Marx apenas se tornou cada vez mais determinado, ou seja, mais complexo e, portanto, uma "totalidade mais total". Em segundo lugar, especialmente no Brasil, deve-se substituir o inglório discurso da cidadania, em prol do controle da produção da materialidade e dos recursos naturais pelos atores produtivos. Trata-se de controlar socialmente as forças produtivas através dos vários mecanismos que a possam realizar transformando o desenvolvimento civilizatório do capital em uma forma que não fosse mais de classes, mas sim humana, social e democrática na mais profunda acepção de raiz dessa palavra. Em sentido teórico isso só é possível por meio da leitura do objetivo último do marxismo que é a emancipação. Para isso é necessário perceber que existe em Marx profunda afinidade entre os conceitos e categorias econômicas de sua obra e os processos políticos, ideológicos, culturais e naturais.

11. Celso Frederico, Crise do Socialismo e Movimento Operário. São Paulo, Editora Cortez, 1994, p. 13.

\begin{tabular}{l|l} 
& \\
\hline Economia e sociedade no capitalismo contemporâneo $\quad$ cadernos cemarx, nํ- 2006 & 109
\end{tabular}

